\title{
Assessment of oxidative stress indicators of West African Dwarf sheep under semi intensive management system
}

Jack, A. A., Jimoh, O. A.* ,Ihejirika, U. G., Uwaeziozi, U. C.and Adenekan, O. O. Department of Animal Science, University of Ibadan, Oyo State. *corresponding Author: abubakarjimoh2011@gmail.com; +2348066058134

\begin{abstract}
Oxidative stress results from increased production of free radicals and reactive oxygen species, and a decrease in antioxidant defense. This study was conducted to assess sexual dimorphism in serum biochemistry and oxidative status of West African dwarflambs. Sixteen each of rams and ewes 8months old were randomly selected from a herd purchase from livestock market, Oyo. The average body weights of the lambs were $12.08 \pm 3.26$ and $12.76 \mathrm{~kg}$ ewes and rams, respectively. Fastened blood samples were collected from the sheep and assayed for serum biochemical, lipid peroxidation, total antioxidant activity, catalase and superoxide dismutase using standard procedures, data obtained were subjected to T-test. The result indicated that both sex had similar serum biochemical indices except total protein. Ewes had significantly higher serum protein than ram. Rams had apparently higher total antioxidant activity and significantly higher serum catalase activity than ewes, while serum lipid peroxidation and superoxide dismutase were statistically similar in both sexes. This indicates that rams have better antioxidant activity than ewes. During oxidative stress prone conditions and environment, measures to boost antioxidant activity of ewes should be emphasized.
\end{abstract}

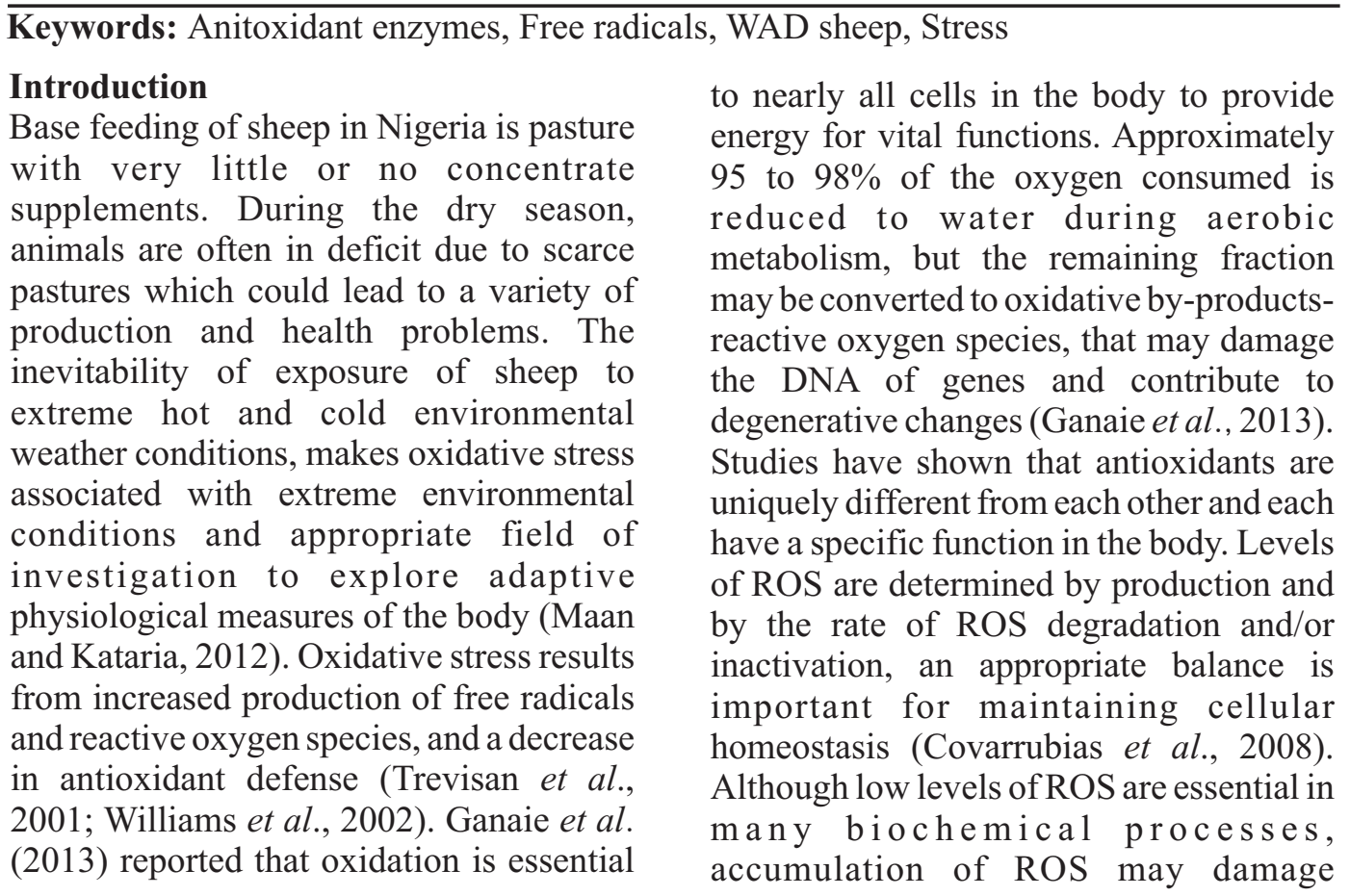


biological macromolecules i.e. lipids, proteins, carbohydrates and DNA (Kumar et al., 2011). External factors such as oxygen exposure (resuscitation; Kumar et al., 2010) heat, trauma, ultrasound, infections, radiations, toxins etc. can lead to increased free radicals and other ROS and may lead to oxidative stress (Halliwell et.al., 1992).

The ROS are produced in all cells, depending on the intensity of aerobic metabolism, especially in activated neutrophils, monocytes, smooth muscle cells and in endothelial cells (Nanda et al., 2007). Disequilibrium between ROS production and inactivation leads to oxidative stress. The organism has enzymatic (e.g. superoxide dismutase, catalase, glutathione peroxidase) and nonenzymatic (e.g. vitamin E) antioxidant mechanisms that work as scavenger for this harmful ROS.

Altan et al. (2003) have demonstrated that heat stress increased lipid peroxidation which is associated with production of large number of free radicals andare capable of initiating peroxidation of polyunsaturated fatty acids. Ralhan et al. (2004) also reported that lipid peroxidation is significantly increased during reticuloruminal impaction in buffaloes.

A major threat to homeostasis and therefore to the integrity of aerobic organisms arises from chemical species possessing one or more unpaired electrons in their outer orbital, called free radicals (Halliwell and Gutteridge, 1997). Oxygen free radicals can develop during several steps of normal metabolic events. Although free radicals have the potential to damage the organism, their generation is inevitable for some metabolic processes. There is limited documentation on oxidative stress markers in Nigerian sheep population. Thus, investigation was carried out on influence of sexual dimorphism in oxidative status and serum biochemistry of West African dwarf Sheep.

\section{Materials and methods}

Thirty-two West African dwarf sheep consisting of 16 ewes and rams each with an average weight of $12.08 \pm 3.26$ and $12.76 \mathrm{Kg}$ respectively were selected from a herd in a livestock market, Oyo, Nigeria. The sheep were quarantined and acclimatized for 4 weeks. The does were dry and all animals were of good conformation. The animals were managed in a semi intensive system, offered concentrate for 2-3 hours in the morning and 6-7 hours for free choice grazing. Blood sample were collected through jugular vein from all animals and serum obtained using standard procedures. Serum biochemical; glucose, total protein, albumin, cholesterol, triglyceride, high density lipoprotein, alkaline phosphatase, alanine amino transferase, aspartate amino transferase, urea and creatinine were carried out using Randox kits and its procedures. Serum was assayed for peroxidation, antioxidant activity, catalase and superoxide dismutase. Serum total antioxidant capacity activities was carried out according to Korecevic, (2001), superoxide dismutase (SOD) was estimated by the method of Marklund and Marklund (1974) adopted by Soon and Tan (2002) and catalase was estimated by Beers and Sizer (1952) method, serum lipid peroxidation was determined using thiobarbituric acid assay according to Ohkawa et al. (1979).

Data obtained in this study were subjected to student's T-test using statistical analysis software SAS 2002.

\section{Result and discussion}

Serum biochemistry of West African dwarf 


\section{Jack, Jimoh, Ihejirika, Uwaeziozi, and Adenekan}

sheep is shown in Table 1. The serum biochemistry of WAD sheep was not significantly affected by sex except for total protein. This showed that both sex have similar physiological status. The differences in serum total protein of WAD sheep is contrary to report of Onasanya et al. (2015) that no significant difference in serum total protein in Uda, Yankassa and Balami sheep.

Table 1: Sexual dimorphism in serum biochemistry of WAD sheep under semi-intensive management system

\begin{tabular}{lllll}
\hline Parameters & Ram & Ewe & \pm SEM & Significance \\
\hline Glucose $\mathrm{mmol} / \mathrm{l}$ & 1.76 & 1.81 & 0.13 & Not sig \\
Total protein g/l & 21.31 & 58.48 & 5.20 & Sig \\
Albumin g/dl & 2.60 & 3.11 & 0.27 & Not sig \\
Cholesterol mmol/1 & 1.13 & 1.46 & 0.13 & Not sig \\
Triglycerides mmol/1 & 0.56 & 0.54 & 0.03 & Not sig \\
High density lipoprotein mmol/1 & 2.72 & 3.22 & 0.58 & Not sig \\
Alanine amino transferase & 5.05 & 6.98 & 1.32 & Not sig \\
Aspartate amino transferase & 14.88 & 18.40 & 1.80 & Not sig \\
Alkaline phosphatase u/L & 1495.87 & 1245.02 & 11.71 & Not sig \\
Creatinine $\mu$ mol/L & 119.43 & 149.99 & 35.71 & Not sig \\
Urea mg/dL & 161.97 & 195.84 & 15.93 & Not sig \\
\hline SEM- & &
\end{tabular}

SEM- standard error of mean; Sig- Significant difference; Not sig- No significantly different

The result of oxidative status of West African dwarf sheep as influenced by sex difference is shown in Table 2. It showed that all oxidative indicator parameters were not affected by sex differences, except catalase activity. Serum catalase of rams was significantly higher than ewes. Though, rams had apparently higher total antioxidant activity than ewes, serum lipid peroxidation was apparently lower in does. This indicates that the significantly higher serum catalase was responsible for the numerical high total antioxidant activity value of ram.

The trend of result showed that superoxide dismutase activities of ewes were slightly higher than rams and this could account for the slightly lower serum lipid peroxidation in ewes. SOD is the first line of defense against free radical accumulation, superoxide isdismutated by SOD to hydrogen peroxide which is further converted to water and other lesser oxygen species by catalase. The role of superoxide dismutase is to accelerate the dismutation of the toxic superoxide produced during oxidative energy processes to hydrogen peroxide and molecular oxygen (Hajimohammadi et al., 2015). Mitochondrial SOD readily converts the bulk of mitochondrial superoxide ions to $\mathrm{H}_{2} \mathrm{O}_{2}$ (Ganaie et al., 2013). The apparently higher antioxidant activity in rams could be attributed to its higher catalase activity which indicates higher scavenging of hydrogen peroxides. Because peroxisome catalase takes care of the cytosolic and mitochondrial peroxides formed during urate oxidation (Oshino and Chance, 1977).

Table 2: Oxidative stress indicators of WA D sheep under semi intensive management system

\begin{tabular}{llll}
\hline Parameters & Ewe & Ram & $\begin{array}{l}\text { Level of } \\
\text { significance }\end{array}$ \\
\hline Total Antioxidant activity (mmol/litre) & $7.07 \pm 6.19$ & $12.34 \pm 10.33$ & $0.18 \mathrm{NS}$ \\
Lipid peroxidation $\left(\mathrm{x} 10^{3} \mathrm{TBARS} / \mathrm{mgprotein}\right)$ & $1.79 \pm 1.37$ & $1.97 \pm 1.79$ & $0.87 \mathrm{NS}$ \\
$\begin{array}{l}\text { Catalase (mmoles of } \mathrm{H}_{2} \mathrm{O}_{2} \\
\text { consumed/min/mgprotein) }\end{array}$ & $24.00 \pm 6.94^{\mathrm{b}}$ & $49.08 \pm 41.10^{\mathrm{a}}$ & $0.011^{* *}$ \\
Superoxide dismutase (U/g) & $0.50 \pm 0.09$ & $0.48 \pm 0.08$ & $0.31 \mathrm{NS}$ \\
\hline$* *$ Significant difference is observed, NS- No significantly different & \multicolumn{3}{l}{}
\end{tabular}


Oxidative stress markers of West African dwarf sheep under semi intensive management system

One of the molecules contributing to oxidative stress is a large decrease in the reducing capacity of cellular redox couples (antioxidants). The importance of oxidative stress indications in lambs has been elicited by works of Kumar et al. (2010) in which he described the excitation of antioxidant enzymes to newborn lambs in response to hyperoxia due to resuscitation and within $24 \mathrm{hrs}$ exposure, suggested that oxygen resuscitated lambs had evidence of systemic oxidative stress over time and cell membrane damage at $24 \mathrm{hrs}$ compared with the room air resuscitated lambs. He indicated that fetal lung antioxidant enzymes; specifically SOD, catalase and gluthatione peroxidase increases during the final 15 to $20 \%$ of intrauterine life (Frank and Sosenko, 1987), and lambs can induce antioxidant activity at $24 \mathrm{hrs}$ in the presence of maximal hyperoxia, suggesting the maturation of its pathways. Kumar et al. (2010) reported that newborn lambs exposed to maximal oxygen had systemic oxidative stress, damage to cell membranes and higher activities of antioxidant enzymes in response to a pro oxidant situation. Kataria et al. (2010) reported that increase activity of serum catalase during hot environmental condition suggested the ability of the animals to provide defense against free radicals and oxidative stress. Environmental conditions associated variations in the catalase activities have been reported by researchers (Marti et al., 2007). Kataria and Kataria (2012) reported effect of PPR on oxidative stress in sheep, the findings suggested the relevance of periodic assessment of oxidative status in tuminants for healthier management through supplementation of proper antioxidants as supportive treatment in PPR and in healthy in-contact animals. Rezapour and Taghinejad-Roudbaneh (2011) reported that late gestation imposed lots of stress of anti-oxidative system of ewes.

\section{Conclusion}

This study has revealed that WAD rams have better antioxidant activity than ewes.During oxidative stress prone conditions and environment, measures to boost antioxidant activity of ewes should be emphasized.

It is recommended that reference values of oxidative stress indicators should be developed in sheep populations. There should be awareness for protection against oxidative stress in different physiological states, production, feeding and management systems for Nigeria livestock species.

\section{References}

Altan, O., Pabuccuoglu, A., Alton, A., Konyalioglu, S. and Bayraktar, H. 2003. Effect of heat stress on oxidative stress, lipid peroxidation and some stress parameters in broilers. Br. Poult. Sci., 4: 545-550.

Beers, R. F. and Sizer, I. W. 1952. A spectrophotometric method for measuring the breakdown of hydrogen peroxide by catalase. $J$ Biol Chem; 195:133-40.

Frank, I., and Sosenko, I. R. 1987. Prenatal development of lung antioxidant enzymes in four species. J. Pediatr. 110: 106-110.

Ganaie, A. H., Shanker, G., Bumla, N. A., Ghasura, R. S. and Mir, N. A. 2013 . Biochemical and Physiological Changes during Thermal Stress in Bovines. $J$ Veterinar Sci Technol 4: 126. doi:10.4172/2157-7579.100012

Hajimohammadi, A., Rajaian, H., Jafari, S. and Nazifi, S. 2015. The effect of different doses of oral salinomysin on oxidative stress 
biomarkers in sheep. J. Veterinar. Sci. Technol. 6:243. Pp 1-6.

Halliwell, B. and Gutteridge, J. M. C. 1997. Free Radicals in Biology and Medicine. $3^{\text {rd }}$ ed. London, Oxford University Press. Free Radicals in Biology and Medicine. $3^{\text {rd }}$ ed. London, Oxford University Press.

Halliwell, B., Gutteridge, J. M. C. and Cross, C. E. 1992. Free radicals, antioxidants and human diseases: Where are we now?. J. Lab. And Clin.Med., 119(6): 598-620.

Kataria, A. K. and Kataria, N. 2012. Evaluation of oxidative stress in sheep affected with peste des petits ruminants. Journal of stress physiology and Biochemistry 8:4 72-77.

Kataria, N., kataria, A. K. and Maan, R. 2010. Evaluation of oxidative stress due to hot environmental condition in healthy Marwari goats from arid tract in India. Philipine Journal of Veterinary and animal Sciences 36(2) 175-184.

Koracevic, D., Koracevic, G., Djordjevic, V., Andrejevic, S. and Cosic, V. 2001. Method for the measurement of antioxidant activity in human fluids .J Clin Pathol; 54:356-361.

Kumar, S., Kumar, Ajeet, B. V. and Meena, K. 2011. Review: Effect of heat stress in tropical livestock and Different strategies for its amelioration. Journal of Stress Physiology \& Biochemistry, Vol. 7 No. 1, pp. 45-54

Kumar, V. H., Patel, A., Swartz, D. D., Wang, H., Wynn, K. A. and Nielsen, L.C. 2009. Exposure to supplemental oxygen and its effects on oxidative stress and antioxidant enzyme activity in term newborn lambs. Pediatr Res 67: 66-71
Maan, K. and Kataria, N. 2012. Evaluation of oxidative stress during adverse environmental conditions in Marwari sheep from arid tracts in India. Animal biology and animal husbandry $A B A H$ Bioflux, 4(2) 38-42.

Marklund, S. L. and Marklund, G. 1974. Involvement of the superoxide anion radical in the autoxidation of pyrogallol and a convenient assay for superoxide dismutase. Eur $J$ Biochem 47:469-74.

Marti, E., Mara, L., Marti, J. I., MuinoBlanco, T. and Cebrian-Perez, J. A. 2007. Seasonal variations in antioxidant enzyme activity in ram seminal plasma. Theriogenology 67:14 46-54.

Nanda, N., Bobby, Z., Hamide, A., Koner, B. C. and Sridhar, M. G. 2007. Association between oxidative stress and coronary lipid risk factors in hypothyroid women is independent of body mass index. Metabolism 56: 1350-1355.

Ohkawa, H., Ohishi, N. and Yagi, K. 1979. Assay for lipid peroxides in animal tissues by thiobarbituric acid reaction. Anal Biochem 95: 351-358.

Onasanya, G. O., Ikeobi, C. O. N., and Sokunbi, B. O. 2015. Implications of breed, sexual dimorphism and age on serum total protein levels in the blood serum of tropically managed sheep. Proceedings of the 49 Annual conference of the Agricultural society of Nigeria "Delta 2015" Volume 49, pp 880883.

Oshino, N. and Chance, B. 1977. Properties of glutathione release observed reduction of organic hydroperoxide, demethylation of 
Oxidative stress markers of West African dwarf sheep under semi intensive management system

aminopyrine and oxidation of some substances in perfused rat liver and their implications for the physiological function of catalase. Biochem J. 162: 509-525.

Ralhan, B., Singh, C., Singha, S. P. S. and Chaudhary, K. S. 2004. Plasma lipid profile, erythrocyte lipid peroxidation and activities of antioxidant enzymes during reticuloruminal impaction in buffaloes. Ind. J. Anim. Sci. 74 (4): 394-395.

Rezapour, A. and TaghinejadRoudbaneh, M. 2011. Effects of food restriction on oxidative stress indices in Ghezel ewes. Journal of Animal and Veterinary advances 10:8, 980-986.
Soon, Y. Y. and Tan, B. K. H. 2002. Evaluation of the hypoglycemic and anti-oxidant activities of Morinda officinalis in streptozotocininduced diabetic rats. Singapore Med. J. 43:77-85.

Trevisan, M., Browne, R., Ram, M., Muti, P. and Freudenheim, J. 2001. Correlatesof markers of oxidative status in the general population. Am J Epidemiol 154:348-356.

Williams, C. A., Kronfeld, D. S., Hess, T. M., Saker, K. E. and Waldron, J. N. 2002 . Antioxidant supplementation and subsequent oxidative stress of horses during an 80-km endurance race. J Anim Sci 82: 588-594.

Received: $15^{\text {th }}$ November, 2016 Accepted: $23^{\text {rd }}$ February, 2017 